Neve, H.H. and Wandahl, S. (2018). "Towards identifying Making-Do as lead waste in refurbishment projects." In: Proc. 26 th Annual Conference of the International. Group for Lean Construction (IGLC), González, V.A. (ed.), Chennai, India, pp. 1354-1364. DOI: doi.org/10.24928/2018/0236. Available at: www.iglc.net

\title{
TOWARDS IDENTIFYING MAKING-DO AS LEAD WASTE IN REFURBISHMENT PROJECTS
}

\author{
Neve, H.H. ${ }^{1}$, Wandahl, S. ${ }^{2}$
}

\begin{abstract}
Refurbishment projects have shown declining productivity in the last decades. At the same time, refurbishment activity is increasing rapidly worldwide to achieve a more sustainable built environment. Thus, understanding reasons for the low productivity is a key aspect to reach environmental as well as economical sustainability. The aim of this research has been to identify Making-Do in refurbishment projects and the reasons behind it. A case study research approach has been used to collect data by actively participating in weekly Last Planner System meetings, observing work in progress on-site on three projects and conducting work sampling studies on six trades. The research showed that Making-Do is highly likely to be both the prevailing and lead waste form in all of the three cases, and that insufficient management of production was the main cause. This was found by firstly identifying an overlap between known impacts of Making-Do from literature and the most occurring negative impacts observed in the cases. Secondly, finding that talking generally contained the biggest potential for being reduced and that this potential had an apparent correlation with Making-Do. This research is an important step towards understanding Making-Do in refurbishment projects and how to detect and reduce lead waste in refurbishment, and to improve construction productivity.
\end{abstract}

\section{KEYWORDS}

Lean Construction, Refurbishment, Work Sampling, Waste, Making-Do

\section{INTRODUCTION}

The Danish government has a goal of being $\mathrm{CO}_{2}$ neutral by 2050 by launching 21 initiatives, with one aimed at reducing the energy consumption of existing buildings by 35\%(Danish-Government 2014). Reducing the energy consumption of existing buildings will provide a significant contribution seen in the light of Ravetz's (2008) work, estimating that $75 \%$ of all existing buildings will still be in use by 2050 . To signify the

\footnotetext{
1 PhD Student, Department of Engineering, Aarhus University, Nordre Ringgade 1, 8000 Aarhus C, Denmark, +45 28791838, hn@eng.au.dk

2 Professor, Department of Engineering, Aarhus University, Nordre Ringgade 1, 8000 Aarhus C, Denmark, +45 41893216, swa@eng.au.dk
} 
importance of refurbishing existing buildings, numbers from The Danish Government(2014) show that $40 \%$ of all energy consumed relates to heating and running equipment in existing buildings. Numbers from the Danish construction sector show that refurbishment now has a $42 \%$ bigger market share than new build (refurbishment $35,8 \%$ and new build $25,2 \%$ ). Despite the importance of refurbishment, statistics show that productivity in refurbishment has been declining for the past two decades with new build going slightly up(Tænketank-om-Bygningsrenovering 2012).

Declining productivity in a large and growing domestic market will have negative economic consequences, sounder standing the reasons for low productivity is urgent. Furthermore, a report by LCICG(2012) shows that investing in optimising the building process through innovations contains the largest potential for saving carbon emissions in refurbishment and new build projects when working with a 2050timeline.

\section{REFURBISHMENT}

Refurbishment has a higher complexity and uncertainty than new build due to several circumstances: existing site and building conditions with low accessibility before actual start of construction, tenants either living in the buildings or being temporarily relocated during refurbishment work, less space and more uncertain work conditions. This combined with the fact that some refurbishment work is significantly different from new build(Egbu et al. 1998) create a project environment that is difficult to manage. Furthermore, anill-managed building process also creates problematic consequences in the value perspective of a refurbishment project because the tenants (end-users) have to accept dust and noise from construction(Holm and Bröchner 2000).

To solve the problem of managing refurbishment projects, Kemmer and Koskela (2012) propose lean theory. $\operatorname{In}(2013)$ Kemmer et al. presented several cases of refurbishment projects with superior performance, managed by lean principles. Despite proven results, lean use is still often limited(Kemmer et al. 2013).This tendency is also visible in this research, and the negative consequences are showcased in the results and discussion.

\section{WASTE}

To optimise production, waste must be removed and for this Oh no (1988)defined the seven intuitive, recognisable waste types. These waste types can be recognised and understood by Going Gemba (going to the site and doing visual observations) and then take action to remove them.

Since manufacturing and construction constitute two different production systems(Ballard and Howell 1998), the inherent waste is also different, thus Ohno's seven waste categories do not have the same intuitive nature when applied in construction(Bølviken and Koskela 2016). Koskela (2004) adds to this by defining the eighth construction specific waste, Making-Do: "Making-Do as a waste refers to the situation where a task is started without all its standard inputs, or the execution of a task is continued although the availability of at least one standard input has ceased".

The primary aim of this research has been to identify Making-Do, its significance and impaction refurbishment projects. This work is a step in the right direction of 
understanding the reasons for low productivity in refurbishment projects and adds to closing a knowledge gap in the current state of the art on prevailing waste forms and reasons for low productivity in refurbishment projects. The research will, in the following, be presented in sections with content and sequence as follows: method, results, discussion, conclusion and references.

\section{METHOD}

Three social housing refurbishment projects were followed for 12,8 and 8 weeks respectively. A multiple case study approach with the use of multiple methods was used to obtain higher reliability and validity in the collected data(Yin 2009). The use of multiple methods was applied to achieve a qualitative contextual understanding combined with an in-depth knowledge of the construction work observed. The methods applied were 1) interview and observation sand 2) work sampling (WS). First, the three selected cases are presented. Second, the contextual qualitative interviews and observations are described. Third, the quantitative WS method is outlined including work description, chosen categories of activities for data collection and uncertainties for the method.

\section{CASES}

All cases were planned to go through a comprehensive refurbishment including total renovation of the building envelope and the interior, including installations. All projects used limited parts of Location Based Planning (LBS) and Last Planner System (LPS) to manage their production. LPS weekly meetings with foremen were held to register weekly planned activities. Percent Planned Complete (PPC) was only calculated in weeks where the research team participated in the meetings. Look-ahead planning and restraint analysis were not explicitly used. Case details are displayed in Table1 below.

Table 1: Data collection from three cases

\begin{tabular}{llll}
\hline \multicolumn{1}{c}{ Case 1 } & \multicolumn{1}{c}{ Case 2 } & \multicolumn{1}{c}{ Case 3 } \\
\hline Contract type & Turnkey contractor & General contractor & General contractor \\
Contract value & USD 53 millions & USD 31 millions & USD 55 millions \\
Contract period & $2015-2018$ & $2017-2021$ & $2016-2019$ \\
Apartments & 297 & 291 & 601 \\
m2 & 23.700 & 22.800 & 46.500 \\
Stories & Basement to 2 & Basement to 2 & Basemen to 3 \\
Originally built & $1960 \mathrm{~s}$ & $1950 \mathrm{~s}$ & $1950 \mathrm{~s}$ \\
Project followed & 12 weeks & 8 weeks & 8 weeks \\
PPC measured for & 8 weeks & 5 weeks & 5 weeks \\
PPC percentage & $54 \%$ & $46 \%$ & $60 \%$ \\
WS-study & 6 trades & 0 & 0 \\
\hline
\end{tabular}

\section{Interviews}

Unstructured and semi-structured interviews were conducted on all cases (Ritchie et al. 2005). Five to six craftsmen from different trades were interviewed semi-structured. In addition, one unstructured interview with the PM responsible for processes and planning and one unstructured interview with the PM responsible for the interviewed craftsmen 
were conducted. The people interviewed in case 1 were all working with the studied trades.

\section{WORK-SAMPLING METHOD}

A general description of work for the six observed trades is presented below. This is followed by a section describing the WS method used in this research.

\section{Work Description}

The work of the six trades can be regarded as traditional refurbishment work. The construction site was unlocked and unguarded outside working hours, so all contractors had to move tools back and forth between the construction site and cars/containers to prevent theft (distance $40-50 \mathrm{~m}$ ). The following crafts were studied: Decking (two carpenters), Flooring (four specialists) Kitchen (two specialists)Plumbing (two plumbers)Painting (two painters) Façade (four specialists).

\section{Categories for work-sampling data collection}

The work-sampling study approach was used to collect and categorise work for the six different crafts. The method is quantitative and based on direct visual observations(Terp et al. 1987). The method is mainly used for understanding how workers' time is being used. Josephson and Björkman (2013) emphasise that this method is not capable of directly measuring productivity, which must be kept in mind when interpreting the results.

In the collection of data, the lean tradition has previously used only two categories: value-adding/productive and non-value-adding/waste. Later, this has been expanded into three categories: direct work, indirect work and waste(Womack and Jones 1996). These three categories were adopted in this research as overall categories to better understand the details of the observations in Indirect Work and Waste. Indirect Work and Waste were divided into three sub-categories with indirect work being: Talking, Preparation and Transport, and Waste being: Walking, Gone and Waiting. All categories are tabulated and described in Table 2. All categories were discussed with the workers observed to secure that the categories were sufficient and adequate to describe their work.

Table 2: Definition and description of observation categories

\begin{tabular}{ll}
\hline Category & Description \\
\hline Production & $\begin{array}{l}\text { Activities that physically add value to the product, processing of materials or } \\
\text { assembling of a kitchen element. }\end{array}$ \\
Talking & $\begin{array}{l}\text { The time used to discuss drawings or work at hand, conversations with } \\
\text { persons outside the crew such as tenants or managers. There is no distinction } \\
\text { between professional and private talk. }\end{array}$ \\
Preparation & $\begin{array}{l}\text { Non-value adding handling of materials and elements, adjustment and cleaning } \\
\text { of machines and tools, looking for tools or materials and measuring and } \\
\text { marking. }\end{array}$ \\
Transport & $\begin{array}{l}\text { Driving in a truck to move materials, carrying materials or tools from one place } \\
\text { to another. }\end{array}$
\end{tabular}


Walking Walking without carrying any tools or materials from one place to another.

Gone Time absent from the construction site such as visits to the toilet and smoking.

Waiting Time spent waiting for co-workers, information and materials.

\section{Uncertainties in work-sampling}

Observations were done in random intervals of between 1 and $7 \mathrm{~min}$. (on average 15 per hour), each time noting the current activity of the workers into one of the seven categories. This approach was used to avoid the risk of synchronising observations with given work intervals. Categorising each observation should be done immediately and without any subjectivity. Unfortunately, reality dictates otherwise because all workers cannot be categorised at the same time(Terp et al. 1987). Furthermore, some observations can be difficult to categorise, but since no observations can go in-between categories, these must be placed in one of the seven categories, representing an inherent uncertainty. To accommodate these uncertainties, both statistical analysis and stabilisation graphs have been done as described by Terp et al.(1987), but only the statistical analysis is presented in the results. Data was collected manually with pen and paper, so observations could be done simultaneously.

\section{RESULTS}

The results from this case study consist of interviews and observations including PPC measurements and a WS-study of six different trades.

\section{INTERVIEWS AND OBSERVATIONS}

Interviews and observations drew a consistent picture of the three projects showing that there is only little trust in oral agreements made regarding weekly work plans. The lack of trust was observed to be a direct consequence of insufficient production management.

Interviews with workers revealed that unhealthy and out of sequence activities were very often started. And, that healthy activities regularly deteriorated due to unknown existing conditions and previous activities not being finished as planned or being outside of scope. All craftsmen agreed that increased reliability of production plans would increase effectiveness. When craftsmen from the WS-study were introduced to the results, they all identified several categories containing opportunities for optimisation, but talking most often stood out as having the largest potential. They also noted that bad planning often resulted in:1) talking, 2) transportation of tools and materials and 3) leaving unfinished work because other trades had more important work to do.

The five most common negative occurrences from on-site observations are listed here, exemplifying the above:1) large amounts of talking on-site because planning and problem solving now had to be done within planned production time, 2)frustrations, 3)breach of HSE regulations, 4)overloaded and empty locations and 5)activities started out of sequence.

When PMs from the turnkey/general contractor were asked about the biggest planning challenges, a combination of two things stood out: firstly, insufficient and inadequate 
design material and secondly, little or no access to the apartments until a few days before the actual start of construction, making control of design and planning very difficult.

PPC measurements were also done for 8 weeks on case 1 and $2 \times 5$ weeks on cases 2 and 3,respectively, giving an overall average of 53\% with case 1 at $54 \%$ [min: $32 \%$; max: $70 \%$, case 2 at $46 \%$ [33\%; 60\%] and case 3 at $60 \%$ [42\%; 74\%].

\section{WORK SAMPLING}

Figure 1 presents an overview of the relative frequencies in the three overall categories: Direct Work, Indirect Work (Talking, Preparation and Transport) and Waste (Walking, Gone and Waiting) for the six trades, Decking, Flooring, Kitchen, Plumbing, Painter and Façade, followed by a weighted case average. The results are based on 6,324observations. The relative frequencies for the seven categories within each of the six trades are tabulated in Table 3.

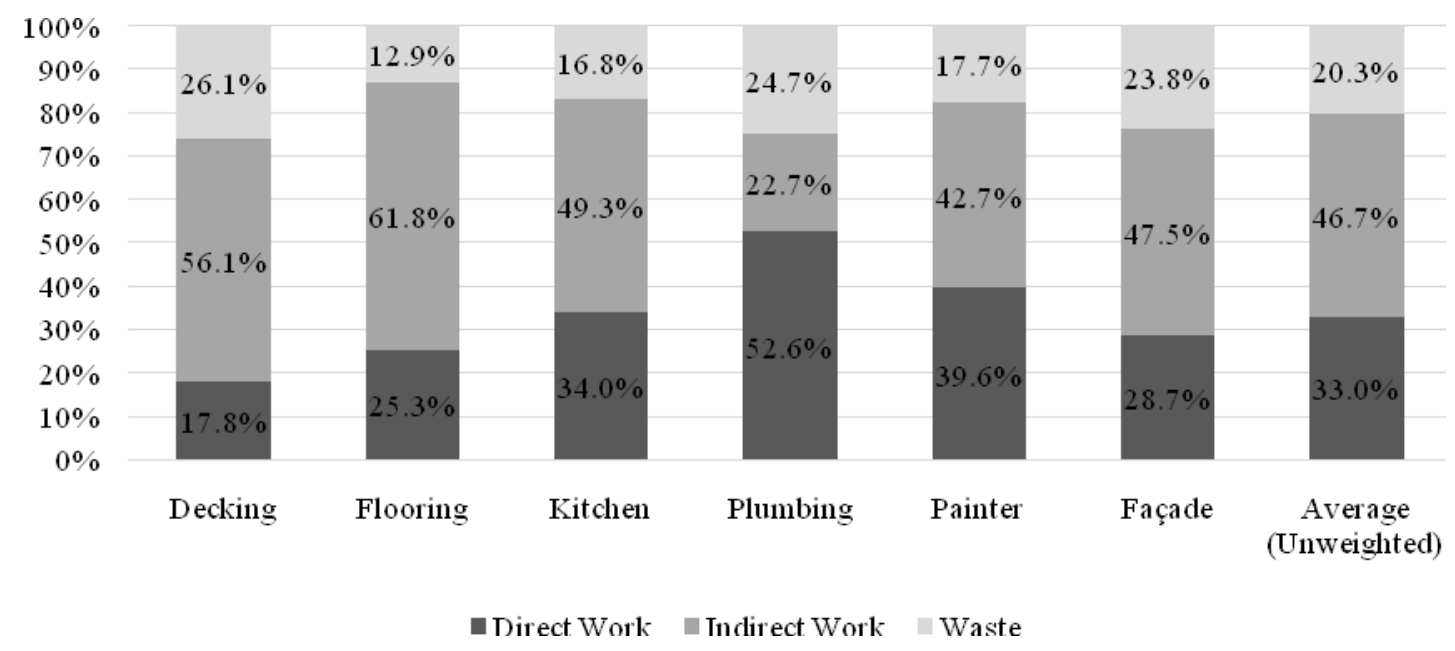

Figure 1: Relative frequencies divided into three categories

To accommodate uncertainties in the WS-study, both statistical analysis and stabilisation graphs have been used (graphs are not displayed in this paper).

Results from the WS-study and the following statistical analysis are displayed in Table 3 for all six trades and have been done according to Terp et al.(1987). The tables present $\overline{\mathbf{p}}$ (relative frequency), $\mathrm{n}$ (number of observations) and $\pm 2 \cdot \delta$ ( $\delta$, one standard deviation) for the main categories: Direct Work, Indirect Work and Waste. $\overline{\mathbf{p}}$ for the three main categories lies within the span of $\pm 2 \cdot \delta$ with a $95,5 \%$ certainty where

$$
2 \cdot \delta= \pm 2 \sqrt{\frac{\overline{\mathbf{p}}(100-\overline{\mathbf{p}})}{\mathbf{n}}}
$$

The last rows in the tables below show $\bar{p}$ for each of the seven subcategories. Statistical analysis on these were left out since $\mathrm{N}$ is low for some subcategories, thus statistical validity becomes low. Moreover, when comparing with other research, 
Neve, H.H., Wandahl, S.

subcategories often vary, leaving the three main categories as most relevant for comparison as pointed out by Josephson and Björkman (2013).

Table 3: WS-study data from six trades

\begin{tabular}{|c|c|c|c|c|c|c|c|c|}
\hline \multicolumn{9}{|c|}{ Decking, $N=847$} \\
\hline Work types & & Direct & & Indirect & & & Waste & \\
\hline $\bar{p}$ & (\%) & 17,8 & & 56,1 & & & 26,1 & \\
\hline $\mathrm{n}$ & & 151 & & 475 & & & 221 & \\
\hline $\pm 2 \cdot \delta$ & $(\%)$ & 2,6 & & 3,4 & & & 3,0 & \\
\hline Category & & Prod. & Talk. & Prep. & Trans. & Walk. & Gone & Wait. \\
\hline $\bar{p}$ & $(\%)$ & 17,8 & 11,9 & 35,5 & 8,6 & 8,5 & 15,8 & 1,8 \\
\hline \multicolumn{9}{|c|}{ Flooring, $\mathrm{N}=991$} \\
\hline Work types & & Direct & & Indirec & & & Waste & \\
\hline $\bar{p}$ & $(\%$ & 25,3 & & 61,8 & & & 12,9 & \\
\hline$n$ & & 251 & & 612 & & & 128 & \\
\hline $\pm 2 \cdot \delta$ & $(\%)$ & 2,8 & & 3,1 & & & 2,1 & \\
\hline Category & & Prod. & Talk. & Prep. & Trans. & Walk. & Gone & Wait. \\
\hline $\bar{p}$ & $(\%)$ & 25,3 & 16,5 & 27,2 & 18,0 & 6,0 & 3,0 & 3,9 \\
\hline \multicolumn{9}{|c|}{ Kitchen, $N=536$} \\
\hline Work types & & Direct & & Indirect & & & Waste & \\
\hline $\bar{p}$ & $(\%)$ & 34,0 & & 49,3 & & & 16,8 & \\
\hline $\mathrm{n}$ & & 182 & & 264 & & & 90 & \\
\hline $\pm 2 \cdot \delta$ & $(\%)$ & 4,1 & & 4,3 & & & 3,2 & \\
\hline Category & & Prod. & Talk. & Prep. & Trans. & Walk. & Gone & Wait. \\
\hline $\bar{p}$ & $(\%)$ & 34,0 & 12,1 & 27,8 & 9,3 & 8,8 & 6,5 & 1,5 \\
\hline \multicolumn{9}{|c|}{ Plumbing, N=740 } \\
\hline Work types & & Direct & & Indirect & & & Waste & \\
\hline $\bar{p}$ & $(\%)$ & 52,6 & & 22,7 & & & 24,7 & \\
\hline $\mathrm{n}$ & & 389 & & 168 & & & 183 & \\
\hline $\pm 2 \cdot \delta$ & $(\%)$ & 3,7 & & 3,1 & & & 3,2 & \\
\hline Category & & Prod. & Talk. & Prep. & Trans. & Walk. & Gone & Wait. \\
\hline $\bar{p}$ & $(\%)$ & 52,6 & 9,9 & 10,1 & 2,7 & 4,6 & 18,9 & 1,2 \\
\hline \multicolumn{9}{|c|}{ Painter, $\mathrm{N}=813$} \\
\hline Work types & & Direct & & Indirect & & & Waste & \\
\hline $\bar{p}$ & (\%) & 39,6 & & 42,7 & & & 17,7 & \\
\hline$n$ & & 322 & & 347 & & & 144 & \\
\hline $\pm 2 \cdot \delta$ & $(\%)$ & 3,4 & & 3,5 & & & 2,7 & \\
\hline Category & & Prod. & Talk. & Prep. & Trans. & Walk. & Gone & Wait. \\
\hline $\bar{p}$ & $(\%)$ & 39,6 & 21,8 & 14,8 & 6,2 & 7,4 & 9,7 & 0,6 \\
\hline \multicolumn{9}{|c|}{ Facade, $N=2270$} \\
\hline Work types & & Direct & & Indirect & & & Waste & \\
\hline $\bar{p}$ & (\%) & 28,7 & & 47,5 & & & 23,8 & \\
\hline $\mathrm{n}$ & & 687 & & 1139 & & & 571 & \\
\hline $\pm 2 \cdot \delta$ & $(\%)$ & 1,8 & & 2,0 & & & 1,7 & \\
\hline Category & & Prod. & Talk. & Prep. & Trans. & Walk. & Gone & Wait. \\
\hline $\bar{p}$ & (\%) & 28,7 & 6,4 & 21,9 & 19,3 & 9,9 & 7,2 & 6,7 \\
\hline
\end{tabular}




\section{DISCUSSION}

Reducing the embedded energy in the execution phase of refurbishment projects can be achieved by initiatives such as extra insulation of site offices and facilities, construction site heat reduction at night, etc. But to significantly reduce the embedded energy, we must optimise productivity, reduce execution time and hereby remove the energy use. To optimise productivity, we must know the current state, potentials and reducible wastes.

The results section presents the current state for three similar refurbishment projects with the following five negative impacts frequently occurring in all cases:1) lots of talking, 2) frustrations, 3) breach of HSE regulations, 4) overloaded and empty locations,5) activities started out of sequence. In addition, a 53\% PPC average on cases 1,2 and 3was measured. Further, a WS-study was conducted on case 1 giving a deep insight into the structural composition of the time used to execute work on-site with a case average (un weighted) at: Direct Work 33,0\%, Indirect Work 46,7\% and Waste $20,3 \%$. The consistent picture in all three cases also means that the WS-study from case 1 can indicate how work time is structured in cases 2 and 3.

To understand if an optimisation potential is present in the three cases, a look at ten other PPC studies makes a good starting point. The average PPC achieved across different construction types with lean use was on average above $70 \%$ in the range of [67\% ; 100\%] (AlSehaimi et al. 2009; Ballard 2000; Lindhard and Wandahl 2014) and reveals a potential for optimising plan reliability with at least $32 \%$ (from $53 \%$ to $70 \%$ ), which is significant and worth pursuing. Unfortunately, PPC measurements are only addressing planning reliability and not productivity (direct work) and waste removal.

The productivity (direct work) measured [18\%; 53\%] are examined to understand productivity potentials. Analysing twenty WS-studies and own results shows high variance, even within the same case and trades (e.g. plumbing), making baseline comparison difficult. WS-studies included in analysis: 1) Gouett et al. (2011) six cases of either power, petroleum or petrochemical construction projects, direct work measurement [27\% ; 42\%], 2) Josephson and Björkman's (2013) eight different cases of plumbing work, direct work measurements $[9,3 \%$; 18,5\%], 3) Shahtaheri et al. (2014)six construction projects of either natural gas or water treatments plants, directwork measurements $[29 \% ; 37 \%]$.

Context and field of work are highly influential, making it difficult to create valid productivity (direct work) baseline rates (Shahtaheri et al. 2014). Nevertheless, using WS-results in a continuous optimisation process has shown significant results (Gouett et al. 2011) because it creates an informed starting point for both craftsmen and management to address optimisation opportunities (Josephson and Björkman 2013).

The WS-study results were also used in this research to start an informed talk about optimisation opportunities. This approach was highly rewarding and revealed several possibilities across the seven observation categories. It also revealed talking as the category with the overall highest potential for being reduced if plan reliability increases across trades. From the researcher's point of view, talking is a logical consequence of bad planning and missing input. A normal reaction to task uncertainties is talking among craftsmen followed by management involvement. This talking, caused by missing input, 
often leads to change of plans, moving tools and materials, leaving unfinished work, etc. This domino effect of wasted time is what Koskela et al. (2013) describe as a chain of wastes where one waste causes a chain of other wastes such as walking, waiting, talking, preparation, transportation, etc. One can of course not claim that talking is a waste form, but rather a clear symptom of the lead waste identified by Koskela (2004) as Making-Do.

Following the connection between excessive talking and Making-Do, a comparison is made between the five most common negative impacts mentioned earlier in the three cases and known impacts of making-Do identified by Firemann et al. (2013) and For moso et al. (2011): 1)reduced productivity, 2) lack of motivation, 3) poor safety, 4) unfinished work, 5) rework, etc. This comparison reveals significant overlaps.

A correlation between the optimisation potential in the category of talking and Making-Do becomes clear when a short summing up is made. Firstly, craftsmen identify talking as having the biggest optimisation potential. Secondly, the occurrence of a Making-Do events initially leads to talking and then to other wastes. Thirdly, Making-Do events are heavily present in all three cases.

This apparent correlation and the fact that all cases are highly identical reveal that Making-Do is highly likely to be the prevailing cause of the declining productivity in refurbishment projects. An explanation for the continuous descent can probably be found in the combination of evolving quality and technical demands combined with an almost absent use of new managerial methods such as Lean Construction.

That the combination of interviews and observations has been so important in understanding the full potentials registered between the lines of the WS-study, for locating optimisation opportunities and lead wastes is due to the fact that waste in construction is a "a parade of singular, evanescent events" (Bølviken and Koskela 2016) not easily identified, even as a fulltime observer in a WS-study.

Experience from this research has convinced the authors that any optimisation attempt starts with a quantified baseline (WS-study and PPC) followed by a future state identified through PPC comparisons and craftsmen and management feedback. This will create a change process in the specific project with ownership from the people doing the job.

\section{CONCLUSION}

The lead waste Making-Do was found to be significant in the three refurbishment projects investigated, and it was found that Making-Do is highly likely to be the prevailing reason for the low productivity in refurbishment projects. Further, an apparent correlation between excessive talking and Making-Doshowed that talking is a valid Making-Do indicator.

Feedback from craftsmen on the WS-study results was a crucial source in waste identification, implying that WS-studies is an effective method for optimisation work.

This research is an important step towards understanding Making-Do in refurbishment projects and to find out how to detect and reduce lead waste to improve productivity. 


\section{ACKNOWLEDGEMENT}

This research is part of the REVALUE research project, a USD 3, 4 million research project on refurbishment of social housing buildings sponsored by The Innovation Fund Denmark.

Furthermore, the support and openness from the case contractors and sub-contractors, and the help from engineering students to collect data has been highly valuable.

\section{REFERENCES}

AlSehaimi, A., Tzortzopoulos, P., and Koskela, L. (2009). "Last Planner System: Experiences From Pilot Implementation in the Middle East." Proc., 17th Ann. Conf. of the Int'l Group for Lean Construction. Taipei, Taiwan, 53-66.

Ballard, G. (2000). "The Last Planner System of Production Control." PhD, School of Civil Engineering, University of Birmingham.

Ballard, G., and Howell, G. (1998). "What Kind of Production Is Construction?" Proc., 6th Ann. Conf. of the Int'l Group for Lean Construction. Guarujá, Brazil.

Bølviken, T., and Koskela, L. (2016). "Why Hasn't Waste Reduction Conquered Construction." Proc., 24th Ann. Conf. of the Int'l Group for Lean Construction. Boston, MA, USA.

Danish-Government (2014). "Strategy for energy renovation of buildings: The route to energy-efficient buildings in tomorrow's Denmark." Build Up.

Egbu, C. O., Young, B. A., and Torrance, V. B. (1998). "Planning and control processes and techniques for refurbishment management." Construction Management and Economics, 16(3), 315-325.

Fireman, M. C., Formoso, C. T., and Isatto, E. L. (2013). "Integrating Production and Quality Control: monitoring making-do and unfinished work." Proc., 21th Ann. Conf. of the Int'l Group for Lean Construction. Fortaleza, Brazil, 515-525.

Formoso, C. T., Sommer, L., Koskela, L., and Isatto, E. L. (2011). "An exploratory study on the measurement and analysis of making-do in construction sites." Proc., 19th Ann. Conf. of the Int'l Group for Lean Construction. Lima, Peru.

Gouett, M. C., Haas, C. T., Goodrum, P. M., and Caldas, C. H. (2011). "Activity Analysis for Direct-Work Rate Improvement in Construction." J. Constr. Eng. Manage, 137(12).

Holm, M. G., and Bröchner, J. (2000). "The effects of craftsman-user interaction." Facilities, 18(13/14), 535-545.

Josephson, P. E., and Björkman, L. (2013). "Why do work sampling studies in construction? The case of plumbing work in Scandinavia." Engineering, Construction and Architectural Management, 20(6), 589-603.

Kemmer, S., and Koskela, L. (2012). "Developing a Lean Model for Production Management of Refurbishment Projects." Proc., 20th Ann. Conf. of the Int'l Group for Lean Construction. San Diego, USA.

Kemmer, S., Koskela, L., and Nykänen, V. (2013). "Towards a lean model for production management of refurbishment projects." VVT Technology, 94, www.vtt.fi. 
Koskela, L. (2004). "Making-Do - The Eighth Category of Waste." Proc., 12th Ann. Conf. of the Int'l Group for Lean Construction. Helsingør, Denmark, 1-10.

Koskela, L., Bølviken, T., and Rooke, J. (2013). "Which are the wastes of construction?" Proc., 21th Ann. Conf. of the Int'l Group for Lean Construction. Fortaleza, Brazil.

LCICG (2012). "Technology Innovation Needs Assessment (TINA) - Non-Domestic Buildings Summary Report." LCICG: Low Carbon Innovation Coordination Group.

Lindhard, S., and Wandahl, S. (2014). "Exploration of the reasons for delays in construction." International Journal of Construction Management, 14(1), 36-44.

Ravetz, J. (2008). "State of the stock - What do we know about existing buildings and their future prospects?" Energy Policy, 36(12), 4462-4470.

Ritchie, B. W., Burns, P. M., and Palmer, C. A. (2005). Tourism research methods: integrating theory with practice, Cabi Publishing.

Shahtaheri, M., Nasir, H., and Haas, C. T. (2014). "Setting baseline rates for on-site work categories in the construction industry." J. Constr. Eng. Manage., 141(5).

Taiichi, O. (1988). Toyota Production System: Beyond Large-Scale Production, Productivity Press Inc.

Terp, B. E., Christiansen, N. M., and Lindegaard, I. M. (1987). Metode Styring Produktionsteknik [Method Management - Production Technology], Erhversskolernes Forlag, Denmark.

Tænketank-om-Bygningsrenovering (2012). "Fokus på Bygningsrenovering [Focus on Building Refurbishment]." Grundejernes Inversteringsfond \& Realdania.

Womack, J. P., and Jones, D. T. (1996). Lean Thinking: Banish Waste and Create Wealth in Your Corporation, Simon and Shuster, New York, NY.

Yin, R. K. (2009). Case Study Research - Design and Methods, SAGE, London, UK. 